\title{
Author Correction: Evolving concepts in systemic lupus erythematosus damage assessment
}

Megan R. W. Barber(D), Sindhu R. Johnson (D), Dafna D. Gladman (1), Ann E. Clarke (i) and Ian N. Bruce (D)

Correction to: Nature Reviews Rheumatology (2021) https://doi.org/10.1038/s41584-021-00611-4, published online 15 April 2021.

In the original version of this article published online, one of the affiliations for lan N. Bruce was incorrectly listed. This error has been corrected in the HTML and PDF of the manuscript.

https://doi.org/10.1038/s41584-021-00620-3 I Published online 27 April 2021

(c) Springer Nature Limited 2021 